\title{
Entomopathogenic fungi as a promising biological control agent against banana fruit scarring beetle, Basilepta subcostata (Jac.) (Chrysomelidae: Coleoptera)
}

Velavan Viswakethu(D, Padmanaban Balakrishanan*, Loganathan Murugan, Baskar Narayana swamy and Uma Subbaraya

\begin{abstract}
Background: Banana fruit scarring beetle (BFSB), Basilepta subcostata (Jac.) (Chrysomelidae:Coleoptera), is an important insect pest feeds on leaf and fingers, which affects the cosmetic value of the fruit. The pest is distributed in Assam, Bihar, West Bengal, Chhattisgarh, and North-eastern Hill regions of India.

Results: The pest is currently managed by foliar spray with insecticides. In order to identify eco-friendly control of the pest, attempts were made to isolate microbial agent and evaluate their potential to control the pest. A total of 27 entomopathogenic fugal isolates were obtained from Odoiporus longicollis (Oliver), Cosmopolites sordidus (Germar), Basilepta subcostata (Jac), and other insect Galleria mellonella (Fabr). Based on colony morphology, the collected fungal isolates were identified as Metarhizium spp. (17) and Beauveria spp. (10). Through ITS sequencing, the fungal isolates were further characterized at species level as B. bassiana (8), B. brongniartii (2), M. anisopliae (8), M. robertsii (6), M. guizhouense (2), and $M$. pinghaense (1). Their sequences were submitted in GenBank and obtained accession numbers. Among 27 isolates tested against $B$. subcostata under laboratory conditions, 3 isolates ( $M$. anisopliae NRCBEPF-36, M. pinghaense NRCBEPF-7 and B. brongniartii NRCBEPF-27) recorded 100\% beetle mortality, followed by 11 isolates with $95-99 \%$ and 13 isolates with $88-93 \%$ within 8 days of treatment.

Conclusion: This study highlights the two native North East India isolates B. brongniartii NRCBEPF-27 (MT151781) and M. anisopliae NRCBEPF-36 (MT140308) showed the significance to use as potential biocontrol agents against banana fruit scarring beetle $B$. subcostata. Further experiments under field conditions are required to evaluate their biological control efficacy against the pest.
\end{abstract}

Keywords: Basilepta subcostata, Metarhizium anisopliae, Beauveria bassiana, ITS region, Bioassay

\section{Background}

Banana is the most important fruit crop and cultivated across 130 countries in the tropical and subtropical region. More than 200 species of insect and non-insect pests have been reported (Simmonds, 1966). The banana leaf and fruit scarring beetle Basilepta subcostata

\footnotetext{
* Correspondence: bpadmanabannrcb@gmail.com

Division of Crop Protection, ICAR-National Research Center for Banana, Tiruchirappalli, Tamilnadu 620102, India
}

(Jacoby) (Chrysomelidae: Coleoptera) is considered as one of the most economically important pests in NorthEastern India (Mishra et al., 2015 and Bhagabati and Deka, 2016). Recently, taxonomic descriptions with illustrations of the genitalia of banana fruit and leaf scarring beetle led to correct identification of B. subcostata (Prathapan et al., 2019).

Entomopathogenic fungal (EPF) strains have been commercialized as a biocontrol agent, and the majority of them have been developed from Ascomycota,

\section{Springer Open}

(c) The Author(s). 2021 Open Access This article is licensed under a Creative Commons Attribution 4.0 International License which permits use, sharing, adaptation, distribution and reproduction in any medium or format, as long as you give appropriate credit to the original author(s) and the source, provide a link to the Creative Commons licence, and indicate if changes were made. The images or other third party material in this article are included in the article's Creative Commons licence, unless indicated otherwise in a credit line to the material. If material is not included in the article's Creative Commons licence and your intended use is not permitted by statutory regulation or exceeds the permitted use, you will need to obtain permission directly from the copyright holder. To view a copy of this licence, visit http://creativecommons.org/licenses/by/4.0/. 
Beauveria spp. (Bals-Criv.) Vuill. (Hypocreales: Clavicipitaceae) and Metarhizium spp. (Metschn.) Sorok. (Hypocreales: Clavicipitaceae) (Rehner et al., 2011 and Velavan et al., 2017). The efficacy of Beauveria spp. has been well established as a potential biocontrol agent of Cosmopolites sordidus (Akello et al., 2008 and Lopes et al., 2013). EPF have been isolated and evaluated against banana stem weevil, Odoiporus longicollis and showed promising results (Padmanaban et al., 2019 and Alagesan et al., 2019). Additionally, the combined use of myco-insecticides and the full or reduced concentration of botanical/chemical insecticides is a promising pest-control option for minimizing adverse chemical effects (Samui et al., 2004 and Choudhary et al., 2010). In this study, an attempt was made to collect, isolate and identify promising EPF as a biocontrol agent for managing scarring beetle of banana.

\section{Methods}

Survey and collection of fungal infected insects

Survey was conducted to collect healthy and infected insects in Tamil Nadu, Bihar, and North-Eastern region (Assam) in India (Table1). Naturally infested banana stem weevils (Odoiporus longicollis Oliver), rhizome weevils (Cosmopolites sordidus Germar), several insect cadavers of leaf scarring beetle (Basilepta subcostata Jac), and other insect pests of the greater wax moth (Galleria mellonella L.) were collected (Table 1) and surface-sterilized with $1 \%$ sodium hypochlorite $(\mathrm{NaOCl})$ for $30 \mathrm{~s}$, followed by 3 washes with sterile distilled water to prevent external saprophytic contaminations. Dead insects were kept in Petri plate lined with a single layer of wet filter paper until signs of muscardine were observed. After that, they were dissected and placed into Petri plates containing potato dextrose agar yeast extract (PDAY) medium

Table 1 Entomopathogenic fungal isolates obtained from different banana pests and Galleria mellonella and their identity

\begin{tabular}{|c|c|c|c|c|c|c|}
\hline S.No & Isolates' name & Species & Isolation sources & Geographic location & Place/state & GenBank accession \\
\hline 1. & NRCB EPF2 & Beauveria bassiana & Odoiporus longicollis & $10.78^{\circ} \mathrm{N} 78.58^{\circ} \mathrm{E}$ & Trichy TN & MT645318 \\
\hline 2. & NRCB EPF27 & B. brongniartii & Basilepta subcostata & $26.72^{\circ} \mathrm{N}, 94.19^{\circ} \mathrm{E}$ & Jorhat Assam & MT151781 \\
\hline 3. & NRCB EPF28 & B. brongniartii & B. subcostata & $26.72^{\circ} \mathrm{N}, 94.19^{\circ} \mathrm{E}$ & Jorhat Assam & MT151784 \\
\hline 4. & NRCB EPF29 & B. bassiana & B. subcostata & $26.31^{\circ} \mathrm{N}, 94.11^{\circ} \mathrm{E}$ & Jorhat Assam & MT151783 \\
\hline 5. & NRCB EPF30 & B. bassiana & B. subcostata & $26.31^{\circ} \mathrm{N}, 94.11^{\circ} \mathrm{E}$ & Jorhat Assam & MT151786 \\
\hline 6. & NRCB EPF32 & B. bassiana & B. subcostata & $26.31^{\circ} \mathrm{N}, 94.11^{\circ} \mathrm{E}$ & Jorhat Assam & MT140307 \\
\hline 7. & NRCBEFPMP1 & B. bassiana & Cosmopolites sordidus & $09.80^{\circ} \mathrm{N}, 77.36^{\circ} \mathrm{E}$ & Theni TN & MK899434 \\
\hline 8. & NRCB EPF22 & B. bassiana & B. subcostata & $25.85^{\circ} \mathrm{N}, 85.78^{\circ} \mathrm{E}$ & Katihar Bihar & MK834817 \\
\hline 9. & NRCB EPF8 & B. bassiana & B. subcostata & $25.09^{\circ} \mathrm{N} 85.31^{\circ} \mathrm{E}$ & Katihar Bihar & MT645316 \\
\hline 10. & NRCB EPF14 & B. bassiana & B. subcostata & $25.09^{\circ} \mathrm{N} 85.31^{\circ} \mathrm{E}$ & Katihar Bihar & MT645319 \\
\hline 11. & NRCB EPF16 & Metarhizium anisopliae & Galleria mellonella & $10.78^{\circ} \mathrm{N} 78.58^{\circ} \mathrm{E}$ & Trichy TN & MK834813 \\
\hline 12. & NRCB EPF17 & M. anisopliae & G. mellonella & $10.78^{\circ} \mathrm{N} 78.58^{\circ} \mathrm{E}$ & Trichy TN & MN888761 \\
\hline 13. & NRCB EPF18 & M. anisopliae & G. mellonella & $10.78^{\circ} \mathrm{N} 78.58^{\circ} \mathrm{E}$ & Trichy TN & MN888763 \\
\hline 14. & NRCB EPF19 & M. robertsii & G. mellonella & $10.78^{\circ} \mathrm{N} 78.58^{\circ} \mathrm{E}$ & Trichy TN & MN889408 \\
\hline 15. & NRCB EPF6 & M. anisopliae & O. longicollis & $10.78^{\circ} \mathrm{N} 78.58^{\circ} \mathrm{E}$ & Trichy TN & MN892391 \\
\hline 16. & NRCB EPF9 & M. anisopliae & O. longicollis & $10.84^{\circ} \mathrm{N} 78.95^{\circ} \mathrm{E}$ & Trichy TN & MK834805 \\
\hline 17. & NRCB EPF7 & M. pinghaense & O. longicollis & $10.78^{\circ} \mathrm{N} 78.58^{\circ} \mathrm{E}$ & Trichy TN & MN892389 \\
\hline 18. & NRCB EPF10 & M. robertsii & O. longicollis & $10.84^{\circ} \mathrm{N} 78.95^{\circ} \mathrm{E}$ & Trichy TN & MN892393 \\
\hline 19. & NRCB EPF11 & M. quizhouense & O. longicollis & $10.84^{\circ} \mathrm{N} 78.95^{\circ} \mathrm{E}$ & Trichy TN & MN892392 \\
\hline 20. & NRCB EPF12 & M. anisopliae & O. longicollis & $10.78^{\circ} \mathrm{N} 78.58^{\circ} \mathrm{E}$ & Trichy TN & MN892390 \\
\hline 21. & NRCB EPF13 & M. robertsii & O. longicollis & $10.78^{\circ} \mathrm{N} 78.58^{\circ} \mathrm{E}$ & Trichy TN & MN892394 \\
\hline 22. & NRCB EPF23 & M. robertsii & O. longicollis & $10.78^{\circ} \mathrm{N} 78.58^{\circ} \mathrm{E}$ & Trichy TN & MN893382 \\
\hline 23. & NRCB EPF24 & M. robertsii & B. subcostata & $25.99^{\circ} \mathrm{N}, 85.59^{\circ} \mathrm{E}$ & Samastipur & MK836090 \\
\hline 24. & NRCB EPF33 & M. robertsii & B. subcostata & $26.48^{\circ} \mathrm{N}, 94.11^{\circ} \mathrm{E}$ & Jorhat Assam & MN893380 \\
\hline 25. & NRCB EPF34 & M. quizhouense & B. subcostata & $26.30^{\circ} \mathrm{N}, 94.11^{\circ} \mathrm{E}$ & Jorhat Assam & MN893383 \\
\hline 26. & NRCB EPF35 & M. anisopliae & B. subcostata & $26.43^{\circ} \mathrm{N}, 94.35^{\circ} \mathrm{E}$ & Jorhat Assam & MT140304 \\
\hline 27. & NRCB EPF36 & M. anisopliae & B. subcostata & $26.43^{\circ} \mathrm{N}, 94.35^{\circ} \mathrm{E}$ & Jorhat Assam & MT140308 \\
\hline
\end{tabular}


amended with antibiotic (1\% yeast extract $0.6 \mathrm{~g}, 100$ $\mu \mathrm{g} / \mathrm{ml}$ chloramphenicol, $50 \mu \mathrm{g} / \mathrm{ml}$ streptomycin, $2 \mathrm{mg}$ crystal violet), and the plates were incubated at $28 \pm 1$ ${ }^{\circ} \mathrm{C}$ and $90 \% \mathrm{RH}$ to facilitate growth and sporulation of the fungus. The cultures were purified using Veen's medium containing Dodine (Veen and Ferron, 1966). Morphologically distinct colonies Beauveria and Metarhizium were picked individually and inoculated on PDAY medium and incubated at $27{ }^{\circ} \mathrm{C}$ for 15 days. After that, the fungal isolates were transferred to PDAY slants and used for further study. Also, slides were prepared (Riddell, 1950) from 5 days old culture for the identification and the cultures were stained with permanent stain (Cotton blue-Lacto phenol) and mounted using dinbutylphthalata in $x y-$ lene (DPX). Identification was done on the basis of morphotaxonomic characters through microscopic inspection of conidia and conidiogenous structure (Bischoff et al., 2009 and Kepler et al., 2014). Also, for a long-term storage, spores were obtained from 5-dayold culture and mixed in $10 \%$ glycerol and stored at $-30{ }^{\circ} \mathrm{C}$ until use.

\section{Molecular characterization through sequencing of ITS region of entomopathogenic fungi (EPF) isolates}

DNA was extracted from 50 to $100 \mathrm{~g}$ of lyophilized mycelium of the fungus from 10-15-day-old cultures grown in potato dextrose broth (PDB) following cetyltrimethylammonium bromide (CTAB) methods (Rogers and Bendich, 1994). Extracted DNA was suspended in EB buffer (10 mMTris-Hcl, pH 8.5) and stored at $-20{ }^{\circ} \mathrm{C}$ until used. The total DNA concentration was measured in spectrophotometer at 280 $\mathrm{nm}$. PCR amplification of the non-coding region of internal transcribed spacer (ITS) of the nuclear ribosomal DNA was performed using a thermal cycler (Bio-Rad, T100 ${ }^{\mathrm{TM}}$ Thermal cycler). Each PCR reaction consisted of $25 \mu \mathrm{l}$ reaction mixture containing $1 \mathrm{X}$ Taq buffer, 0.4-0.6 mM of each primer (ITS1 5'CTCTCCAAACTCGGTCATTT-3' and ITS2 5'ATATGCTTAAGTTCAGCGGGT-3'), $0.2 \mathrm{mM}$ of dNTP mix, 1U of Taq DNA polymerase (GeNei), and 20-50 ng/ $\mu$ l template DNA. The PCR amplification program had one initial cycle at $95{ }^{\circ} \mathrm{C}$ for $3 \mathrm{~min}$, followed by 35 cycles of denaturation at $95{ }^{\circ} \mathrm{C}$ for 1 min, annealing $50{ }^{\circ} \mathrm{C}$ for $45 \mathrm{~s}$ extension at $72{ }^{\circ} \mathrm{C}$ for $2 \mathrm{~min}$, a $2^{\text {nd }}$ final extension at $72{ }^{\circ} \mathrm{C}$ for $10 \mathrm{~min}$. The PCR products were separated on $1 \%$ agarose gel containing $0.05 \%$ of $\mathrm{EtBr}$ in $0.5 \mathrm{x}$ TBE buffer ( $45 \mathrm{mM}$ Tris acetate-1 mM EDTA, pH-8). A 100-bp DNA ladder (GeNei) was run on the same gel, and the size marker and bands were visualized under ultraviolet irradiation. The products $(650 \mathrm{bp})$ from ITS region of
27 isolates were eluted from gel and sequenced using forwards and reverse primers, at sequences facility (Chromus Biotech, Bangalore, India). The sequences were analyzed in BLAST https://blast.ncbi.nlm.nih.gov, biosrv.cab.unina.it/webcap3. Based on similarity, the isolates were named and the sequences were submitted in NCBI-GenBank and obtained accession numbers.

\section{Bioassay of EPF on Basilepta subcostata}

The banana fruit scarring beetles (B. subcostata) were collected from the infested banana field and reared in entomology laboratory of the institute using perforated plastic containers at room temperature. The leaf midribs of cv. Jahaji (a susceptible host) were utilized for feeding the beetles. The entire test beetles were kept in these containers for at least 1 month before use in the experiments for acclimatization. Whereby beetles were observed using a hand lens and males were differentiated from females on the basis of punctuations on their rostrums spreading beyond the point of antennae insertion. These adult beetles were utilized for the present study.

The 27 indigenous EPF isolates were used for bioassay against $B$. subcostata. The cultures were grown on PDAY medium for 10 to 15 days at $25 \pm 0.5{ }^{\circ} \mathrm{C}$. The mycelia mat containing spores were harvested in tube using sterile distilled water $100 \mathrm{ml}$ with continuous stirring the contents in a tube, filtered through a single layer of muslin cloth to remove debris and mycelia. Conidial suspension (CS) was prepared as per the procedure described by Lopes et al. (2013) and Velavan et al. (2017). The conidial concentration was estimated using hemocytometer under light microscope. Subsequently, the conidial suspension was diluted to make a final suspension of $1 \times 10^{5}$ spores $/ \mathrm{ml}$ with $0.1 \%$ Triton X-100, $0.2 \%$ Tween 80 and $0.1 \%$ glycerol. B. subcostata was transferred aseptically to fresh plastic boxes $(10-\mathrm{cm}$ diameter and $30-\mathrm{cm}$ height). The conidial suspension of EPF isolates (27) were swabbed on leaf sheaths (8-10-cm lengths) individually. For comparison, 2 commercial isolates; each $M$. anisopliae and B. bassiana was also included in the experiment. Each treatment had 5 replications, and each replication consisted of 15 beetles. In control, similar numbers of beetles were introduced on to the leaf sheaths treated with water, $0.1 \%$ Triton X-100, $0.2 \%$ Tween 80 , and $0.1 \%$ glycerol alone. Observations were taken on morality of insects at 3,5 , and 8 days after inoculations. Infected insect cadavers were transferred to 
wet chamber and the fungus was re-isolated and confirmed based on culture spore morphology.

\section{Statistical analyses}

Obtained data on beetle mortality rates were Arc Sin transformed and analyzed in Completely Randomized Design using Web Agri Stat Package 2.0 (WASP) https://ccari.res.in/wasp2.0/.

\section{Results}

\section{Isolation and characterization of EPF isolates}

During 2017-2018 in Tamil Nadu, Bihar, and Assam fungal-infected insects such as corm weevil, pseudostem weevil, and scarring beetle besides Galleria were collected, reared, and identified. In total, 27 fungal isolates were isolated and purified from the dead beetles and Galleria larvae Table 1. Based on colony color and spore morphology, the isolates were broadly classified as Metarhizium (17 isolates) and Beauveria (10 isolates) as they produced green and white colonies, respectively. Among the fungal isolates, 13 isolates consisting of 8 Beauveria and 5 Metarhizium were obtained from dead adult beetles of B. subcostata, while 8 isolates of Metarhizium and one isolate of Beauveria were isolated from Odoiporus longicollis. Also, one isolate of Beauveria and 4 isolates of Metarhizium were obtained from adult of Cosmopolites sordidus and larvae of

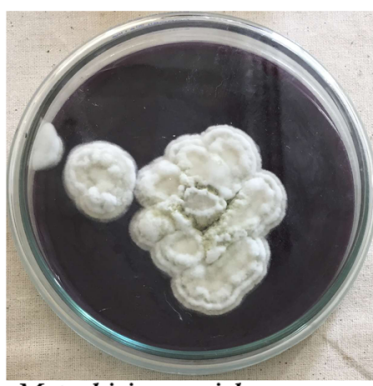

Metarhizium guizhouense

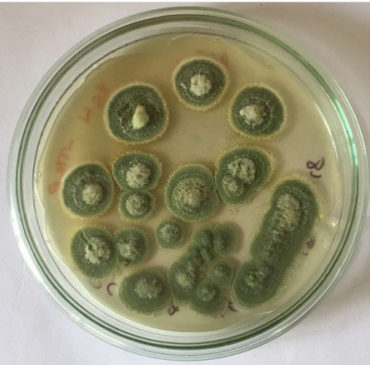

Metarhizium anisopliae

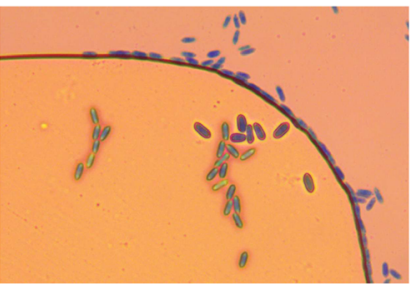

Metarhizium guizhouense

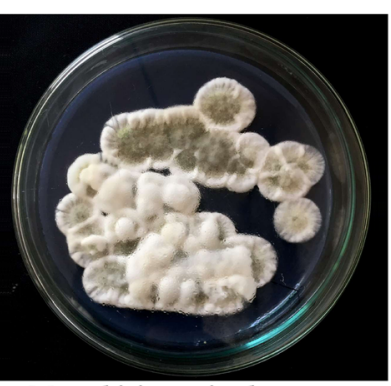

Metarhizium pinghaense

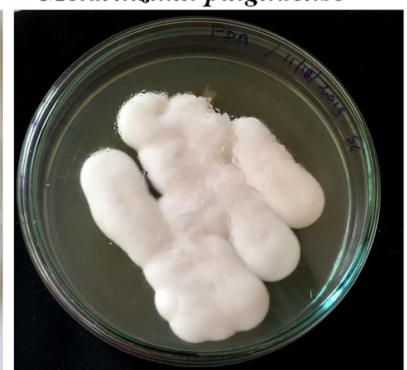

Beauveria bassiana

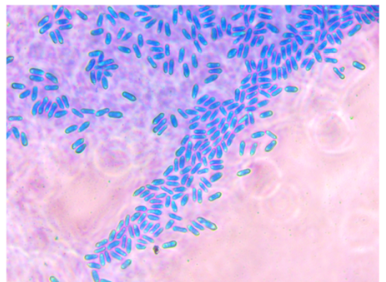

Metarhizium pinghaense

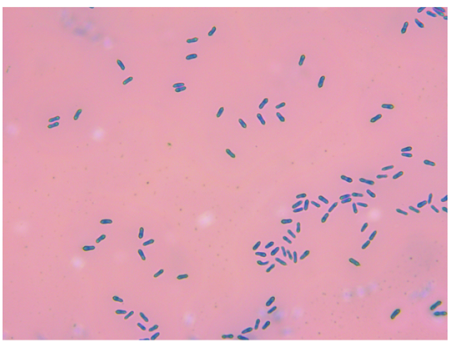

Metarhizium anisopliae

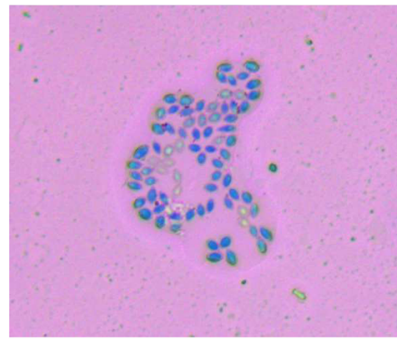

Beauveria bassiana

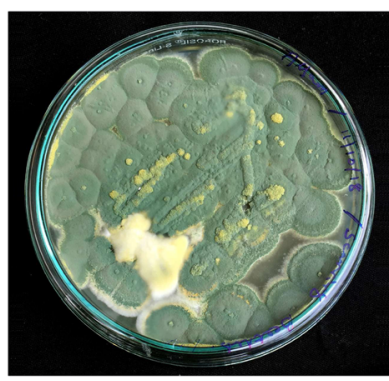

Metarhizium robertsii

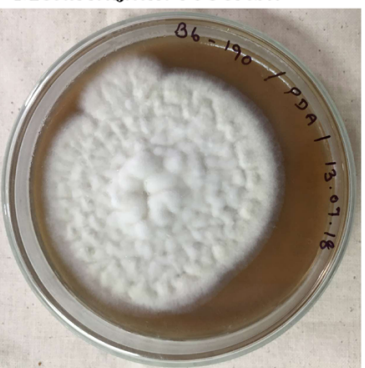

Beauveria brongniartii

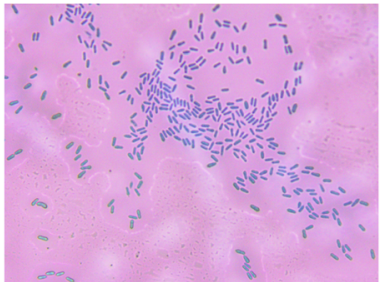

Metarhizium robertsii

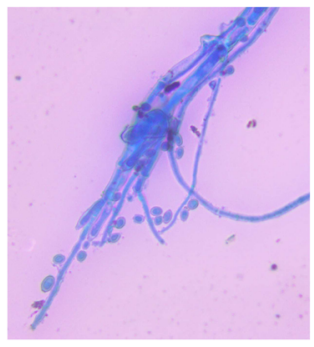

Beauveria brongniartii

Fig. 1 Colony and conidial morphology of entomopathogenic fungi 
Galleria, respectively. Observations on morphological characteristic indicated that Metarhizium isolates produced 4 different colonies and conidial morphologies, while Beauveria showed 2 morphological differences (Fig. 1).
Molecular characterization of EPF isolates

Molecular characterization of EPF cultures through sequencing of ITS regions and BLAST analysis with data base sequences revealed that they belonged to $B$. bassiana (8 isolates), B. brongniartii (2 isolates), $M$.

Table 2 In vitro bio-efficacy of Metarhizium and Beauveria isolates against Basilepta subcostata

\begin{tabular}{|c|c|c|c|c|}
\hline \multirow[t]{2}{*}{ Isolates' name } & \multirow[t]{2}{*}{ Species } & \multicolumn{3}{|c|}{ Per cent mortality (in days after treatment) } \\
\hline & & Day 3 & Day 5 & Day 8 \\
\hline NRCB EPF2 & B. bassiana & $32.7(34.0)$ & $61.7(51.8)$ & $91.7(73.4)$ \\
\hline NRCB EPF8 & B. bassiana & $33.3(35.3)$ & $68.3(55.9)$ & $93.3(77.5)$ \\
\hline NRCB EPF14 & B. bassiana & $28.3(31.6)$ & $56.7(48.8)$ & $93.3(77.9)$ \\
\hline NRCB EPF22 & B. bassiana & $41.3(40.2)$ & $71.7(57.9)$ & $93.3(80.7)$ \\
\hline NRCB EFPMP1 & B. bassiana & $38.3(38.2)$ & $80.0(63.5)$ & $91.7(73.4)$ \\
\hline NRCB EPF27 & B. brongniartii & $45.0(42.1)$ & $95.0(79.3)$ & $100.0(89.4)$ \\
\hline NRCB EPF28 & B. brongniartii & $30.0(32.9)$ & $70.3(56.9)$ & $93.3(77.5)$ \\
\hline NRCB EPF29 & B. bassiana & $38.3(38.2)$ & $78.3(62.8)$ & $91.7(76.0)$ \\
\hline NRCB EPF30 & B. bassiana & $30.0(33.2)$ & $60.0(50.9)$ & $93.3(77.5)$ \\
\hline NRCB EPF32 & B. bassiana & $40.0(39.2)$ & $80.0(63.4)$ & $98.3(85.3)$ \\
\hline NRCB EPF16 & M. anisopliae & $41.7(40.2)$ & $73.3(60.0)$ & 91.7 (73.4) \\
\hline NRCB EPF17 & M. anisopliae & $33.3(35.1)$ & $68.3(56.3)$ & $95.0(79.3)$ \\
\hline NRCB EPF18 & M. anisopliae & $38.3(38.2)$ & $78.3(60.1)$ & 96.7 (81.2) \\
\hline NRCB EPF19 & M. anisopliae & $40.0(39.2)$ & $70.0(57.3)$ & 88.3 (73.6) \\
\hline NRCB EPF6 & M. anisopliae & $45.0(36.2)$ & $76.7(61.1)$ & $91.7(76.0)$ \\
\hline NRCB EPF7 & M. pinghaense & $35.0(42.1)$ & $75.0(62.5)$ & $100.0(89.4)$ \\
\hline NRCB EPF9 & M. anisopliae & $31.7(34.2)$ & $66.7(54.8)$ & $91.7(73.4)$ \\
\hline NRCB EPF10 & M. robertsii & $30.0(32.9)$ & $71.7(58.3)$ & $95.0(82.0)$ \\
\hline NRCB EPF11 & M. quizhouense & $35.0(36.2)$ & $73.3(59.0)$ & $93.3(75.2)$ \\
\hline NRCB EPF12 & M. anisopliae & $40.0(39.2)$ & $75.0(60.1)$ & 96.7 (83.4) \\
\hline NRCB EPF13 & M. anisopliae & 36.7 (37.2) & $78.3(61.1)$ & $95.0(79.3)$ \\
\hline NRCB EPF23 & M. robertsii & 36.7 (37.1) & $78.3(62.5)$ & $98.3(85.3)$ \\
\hline NRCB EPF24 & M. robertsii & 36.7 (37.3) & $78.3(60.0)$ & $95.0(79.3)$ \\
\hline NRCB EPF33 & M. robertsii & $36.7(37.1)$ & $78.3(62.5)$ & $98.3(85.3)$ \\
\hline NRCB EPF34 & M. robertsii & 36.7 (37.1) & 78.362.5) & $98.3(85.3)$ \\
\hline NRCB EPF35 & M. anisopliae & $30.0(42.1)$ & $85.0(79.3)$ & $98.3(85.3)$ \\
\hline NRCB EPF36 & M. anisopliae & $35.0(36.2)$ & $85.0(67.4)$ & $100.0(89.4)$ \\
\hline Commercial & M. anisopliae & 36.7 (36.2) & $78.3(59.0)$ & $98.3(75.2)$ \\
\hline Commercial & M. anisopliae & $36.7(37.1)$ & $78.3(62.5)$ & $98.3(85.3)$ \\
\hline BCRL formulation & B. bassiana & 36.7 (37.1) & $75.0(62.5)$ & $95.0(85.3)$ \\
\hline TARI formulation & B. bassiana & $30.0(37.3)$ & $71.7(60.0)$ & $95.0(79.3)$ \\
\hline Control & Water+Glycerol & $(0.6)$ & $(0.6)$ & 0. (8.8) \\
\hline Coefficient of variation & & 12.814 & 10.218 & 0.608 \\
\hline$C D(0.01)$ & & 9.789 & 12.750 & 1.147 \\
\hline CD (0.05) & & 7.371 & 9.601 & 0.864 \\
\hline
\end{tabular}

${ }^{*} p<0.001$ (highly significant) and $p<0.05$ (significant)

Two-way factorial analysis of variance (ANOVA) at $a=0.05$, CV\% coefficient of variation

Values represent means of three replicates

Values in parentheses represent arcsine transformations 
anisopliae (8 isolates), $M$. robertsii (6 isolates), $M$. guizhouense (2 isolates), and $M$. pinghaense (1 isolate) as they had 100, 94, 99, 99, 100, and100\% homology with NCBI data base sequences of MT635020, AB027381, FJ545286, MF681599, HM055445, and HM055446, respectively, and all the isolates details with GenBank accessions were depicted in Table 1.

\section{Bioassay of EPF isolates on Basilepta subcostata}

All 27 EPF isolates of Beauveria spp. and Metarhizium spp. along with standard commercial isolates were tested against $B$. subcostata in vitro (Table 2, Fig. 2). Invariably, all the isolated strains showed significant mortality rates of the beetle in 3 days after treatment and the effects were on par with 4 commercial isolates. In 5 days after treatment, $M$. anisopliae (NRCBEPF35 and NRCBEPF 36) and B. brongniartii (NRCBEPF27) isolated from $B$. subcastata from Jorhat, Assam recorded 85-95\% mortality rate of the beetle. The effect of the isolate (NRCBEPF27) was significantly better than all commercial isolates and other isolated strains. However, other isolated strains of $M$. anisopliae (NRCBEPF36), M. pinghaense (NRCBEPF 7), and B. brongniartii (NRCBEPF27) are recorded $100 \%$ mortality on the 8 th day of treatment (Table 2).

\section{Discussion}

Scarring beetle is a major problem in banana cultivation especially in North, East, and North East parts of India; Bangladesh; and South East Asia (Prathapan et al., 2019). It causes severe damage to banana, and it has been estimated up to $95 \%$ damage to the crop in different parts of India (Choudhary et al., 2010; Bhagabati and Deka 2016; Saikia et al., 2018 and Daizy et al., 2019). In India, bananas are consumed majorly as raw fruits and some extent as processed food. Therefore, application of chemical pesticides on banana is hugely discouraged. Alternatively, entomopathogens have been promising in management of pests in different crops. However, success of the biocontrol agent is mainly depending on efficacy of specific strains against target pest and performance of such agents in the given environment. Hence, the present study focused to collect EPF isolates from North, North East, and Southern parts of India and screen against $B$. subcostata.

In total, 27 EFP isolates were obtained and based on spore and colony morphologies, and they were characterized (Bischoff et al., 2009; Rehner et al., 2011; Ravindran et al., 2015; and Ramanujam et al., 2015) majorly as Metarhizium (17 isolates) and Beauveria (10 isolates). Molecular identification of fungal species is generally carried out through sequencing of ITS regions (Bischoff et al., 2009; Rehner et al., 2011; Lopes et al., 2013; Kepler et al., 2014; Ravindran et al., 2015; and Ramanujam et al., 2015) and BLAST analysis with data base sequences. Similarly, sequencing of ITS region of EPF cultures revealed that they belonged to $B$. bassiana, B. brongniartii, M. anisopliae, M. robertsii, M. guizhouense, and M. pinghaense. In the present study, majority of isolates were belonging to Metarhizium spp. followed by Beauveria spp. Over all, comparatively Metarhizium isolates out performed than Beauveria isolates against B. subcastata. Though management strategy for lowering infestation of fruit scaring beetle by biopesticide (B. bassiana) was profitable (Samui et al., 2004 and Choudhary et al., 2010), the present study results corroborated with Tuncer et al. (2019) study where Metarhizium isolate showed better results than Beauveria on controlling the coleopteran insect (Ambrosia beetle, Xylosandrus germanus).
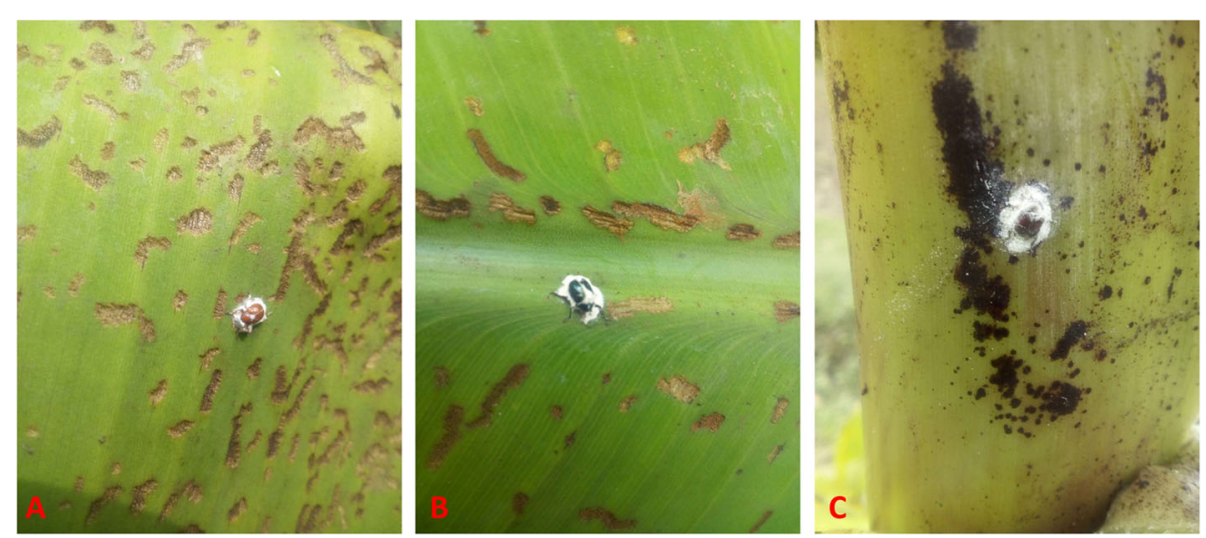

Fig. 2 Effect of EPF native isolates on Basilepta subcastata after 8 days of inoculation. a Insect cadaver fully covered with bright white mycelia of Beauveria brongniartii. $\mathbf{b}$ Insect cadaver fully covered with mycelium of Metarhizium pinghaense. $\mathbf{c}$ Insect cadaver covered with conidia of Metarhizium anisopliae 


\section{Conclusions}

EPF isolates $M$. anisopliae NRCB EPF 35 and NRCB EPF36, and B. brongniartii NRCBEPF27 showed the highest mortality rates of $B$. subcastata. They could be further exploited to extent a wide spread testing of the isolates against the pest in different ecological zone and to commercialize the strain for wider adoptability by end-users. It also gives the way for preparation of consortium, using the best strains such as NRCBEPF36, NRCBEPF7, and NRCBEPF27. Such $M$. anisopliae and B. brongniartii strains with biocontrol properties can fit into the Integrated Pest Management (IPM) of the banana fruit scarring beetle, $B$. subcastata.

\section{Abbreviations}

PDAY: Potato dextrose agar yeast extract; TBE: (Tris/Borate/EDTA); EDTA: Ethylenediaminetetraacetic acid; $\mathrm{NaOCl}$ : Sodium hypochlorite; CTAB: Cetyltrimethylammonium bromide; NCBI: National Center for Biotechnology Information; BFSB: Banana fruit scarring beetle; NRCB: National Research Center for Banana; EPF: Entomopathogenic fungi; ITS: Internal transcribed spacer

\section{Acknowledgements}

We thank Dr. J. Poorani for helping in identification fruit scarring beetle and Director, ICAR-National Research Centre for Banana, Tiruchirappalli (Tamilnadu), for providing the facilities and support in carrying out this work.

\section{Authors' contributions}

W, BP, ML, and US analyzed and interpreted the data; W wrote the manuscript; BP contributed to the taxonomic identification of B. subcastata; BN performed the laboratory experimentation; and $\mathrm{ML}$ edited the manuscript. The authors have read and approved the manuscript.

\section{Funding}

The authors are grateful to the Department of Biotechnology, New Delhi (BT/PR23236/NER95/596/2017), for providing financial support to carry out this work in 2018-2020.

\section{Availability of data and materials}

All data of the study have been presented in the manuscript, and highquality and grade materials were used in this study.

\section{Ethics approval and consent to participate}

Not applicable

\section{Consent for publication}

Not applicable.

\section{Competing interests}

The authors declare that they have no competing interests.

Received: 31 October 2020 Accepted: 12 February 2021

Published online: 17 March 2021

\section{References}

Akello J, Dubois T, Coyne D, Kyamanywa S (2008) Effect of endophytic Beauveria bassiana on populations of the banana weevil, Cosmopolites sordidus and their damage in tissue-cultured banana plants. Entomol Exp Appl 129:157-165

Alagesan A, Tharani G, Padmanaban B, Manivannan S, Jawahar S (2019) An assessment of biological control of the banana pseudostem weevil Odoiporus longicollis (Olivier) by entomopathogenic fungi Beauveria bassiana. Biocatal Agric Biotechnol 20:101262. https://doi.org/10.1016/j. bcab.2019.101262
Bhagabati B, Deka MK (2016) Evaluation of management strategies against leaf and fruit scaring beetle (Nodostmasubcostatum) of banana. Ann Plant Prot Sci 21(1):33-36

Bischoff JF, Rehner SA, Humber RA (2009) A multilocus phylogeny of the Metarhizium anisopliae lineage. Mycologia 101:512-530

Choudhary SK, Mukherjee U, Ahmad MA (2010) Efficacy of biopesticides against banana scarring beetle, Basilepta subcostatum Jacoby. Pest Manag Horti Ecosyst 16(2):120-123

Daizy S, Gaurav K, Inee G (2019) Bioassay of some aqueous plant extracts against leaf and fruit scarring beetle, Nodostoma subcostatum (Jacoby). J Entomol Zool 7(1):1661-1663

Kepler RM, Humber RA, Rehner SA (2014) Clarification of generic and species boundaries for Metarhizium and related fungi through multigenephylogenetics. Mycologia 106(4):811-829

Lopes RB, Mesquita ALM, Tigano MS, Souza DA, Martins I, Faria M (2013) Diversity of indigenous Beauveria and Metarhizium spp. in a commercial banana field and their virulence toward Cosmopolites sordidus (Coleoptera: Curculionidae). Fungal Ecol 6:356-364

Mishra H, Bora DK, Bhattacharyya B, Das D, Baruah K (2015) Population dynamics of banana leaf and fruit scarring beetle, Nodostoma subcostatum Jacoby in Assam. Indian J Entomol 77(3):226-229

Padmanaban B, Baskar N, Velavan V, Uma S (2019) Entomopathogenic fungal association in Banana plants and their possible role in regulation of biotic stress. Symposium on Endophytes and their applications in Agriculture, 24-28 September 2019, UAS,Bengaluru

Prathapan KD, Poorani J, AmrithaKumari S, Anuradha C, Padmanaban B, Thanigairaj R (2019) Species composition and diagnoses of leaf- and fruitscarring beetles (Coleoptera, Chrysomelidae) infesting bananas and plantains (Zingiberales, Musaceae) in the Indian subcontinent. Dtsch Entomol Z 66(2): 179-202

Ramanujam B, Poornesha B, Yatish KR, Renuka S (2015) Evaluation of pathogenicity of different isolates of Metarhizium anisopliae (Metchnikoff) sorokin against maize stem borer, Chilopar tellus (Swinhoe) using laboratory bioassays. Biopestic Int 11(2):0973-483X/11/89-95

Ravindran K, Qiu D, Sivaramakrishnan S (2015) Sporulation characteristics and virulence of Metarhizium anisopliae against subterranean termites (Coptotermes formosanus). Int J Microbiol Res 6(1):01-04

Rehner SA, Minnis AM, Sung G, Jennifer J, Humber RA (2011) Phylogeny and systematics of the anamorphic, entomopathogenic genus Beauveria. Mycologia 103(5):1055-1073

Riddell RW (1950) Permanent stained mycological preparations obtained by slide culture. Mycologia 42:265-270

Rogers SO, Bendich AJ (1994) Extraction of total cellular DNA from plants, algae and fungi. PI Mol Biol Manu 1(8):183-190

Saikia R, Bora DK, Baruah K, Mishra H (2018) Ecofriendly management of banana leaf and fruit scarring beetle Basilepta subcostatum Jacoby in Assam. Indian J Entomol 80(3):794-797./2017/15550

Samui G, Maiti B, Bandopadhyay B (2004) Field evaluation of some insecticidal treatments to control banana scarring beetle (Nodostoma viridipenne Motsch.). Proc Natl. Seminar Banana Industry - Present Scenario and Future Strategies held at BCKV, Kalyani, 11th to 13th June 2004:194-202

Simmonds NW (1966) Pests. In: Bananas, 2nd edn. Longman, London, pp 334-360

Tuncer C, Kushiyev R, Erper I, Ozdemir IO, Saruhan I (2019) Efficacy of native isolates of Metarhizium anisopliae and Beauveria bassiana against the invasive ambrosia beetle, Xylosandrus germanus Blandford (Coleoptera: Curculionidae: Scolytinae). Egypt J Biol Pest Control 29(1):28-38

Veen $\mathrm{KH}$, Ferron P (1966) A selective medium for the isolation of Beauveria tenella and of Metarhiziumanisopliae. J InvertebrPathol 8:268-269

Velavan V, Sivakumar G, Rangeswaran R, Sasidharan TA, Sundararaj R (2017) Metarhizium majus and Metarhizium robertsii show enhanced activity against the coleopteran pests Holotricha serrata L. and Oryctes rhinoceros L. J biolog Cont 31(3):135-145

\section{Publisher's Note}

Springer Nature remains neutral with regard to jurisdictional claims in published maps and institutional affiliations. 